Casos Clínicos

Arch. Esp. Urol., 61, 5 (621-623), 2008

\section{ENUCLEACIÓN EXTRACORPÓREA Y AUTOTRANSPLANTE EN PACIENTE CON RIÑÓN ÚNICO CON CÁNCER RENAL MULTICÉNTRICO DE CÉLULAS CLARAS}

Jeff R. Cortés-González, Jorge A. Arratia-Maqueo, Gerardo E. Ortiz-Lara, Miguel Escobedo' y Adrián Gutiérrez-González.

Servicio de Urología y Servicio de Cirugía de transplantes?. Hospital Universitario Dr. José E. González. UANL.

Monterrey. Nuevo León. México.

Resumen.- OBJETIVO: Demostrar que la cirugía de banco y el autotransplante continúan siendo alternativas vigentes para el tratamiento de casos complejos de cáncer renal.

MÉTODOS: Femenina de 58 años con diagnóstico de cáncer de células renales tratado con nefrectomía radical derecha 13 años antes. Acude al servicio de medicina del dolor tras presentar como único síntoma lumbalgia. En los estudios de imagen para la evaluación de la lumbalgia se realiza el hallazgo de tumoraciones en riñón izquierdo por lo que es referida a nuestro servicio.

Jeff R. Cortés González

Servicio de Urología

Hospital Universitario Dr. José E. González. UANL

Av. Madero y Gonzalitos s/n

Col. Mitras Centro

64780 Monterrey NL. (México).

ircor77@yahoo.com

Trabajo recibido: 21 de septiembre 2007
RESULTADOS: Se realiza abordaje con lumbotomía. Se extrae pieza quirúrgica y se realiza perfusión con solución de EuroCollins y se realiza cirugía de banco. El tiempo isquemia fría antes de la anastomosis vascular fue de 63 min. Se colocó riñón en región pélvica derecha. Hubo diuresis inmediatamente posterior a anastomosis vascular. Se realizó reimplante ureteral tipo Lich-Gregoir. Cursa sus primeras 48 horas postoperatorias sin complicaciones y con diuresis en promedio de $80 \mathrm{cc}$ por hr. Presenta insuficiencia renal aguda, posterior a 6 sesiones de hemodiálisis diuresis normal. Presentó fuga urinaria en anastomosis ureteral que produjo urinoma que se resolvió con drenaje percutáneo guiado por TAC. Doce meses después de la cirugía la paciente esta asintomática, creatinina sérica 1.6 $\mathrm{mg} / \mathrm{dl}$ depuración de creatinina de $60 \mathrm{ml} / \mathrm{min}$, estudios de control con riñón libre de neoplasia.

CONCLUSIONES: La cirugía de banco continúa siendo una opción terapéutica para casos complejos de cáncer renal para evitar que los pacientes sean sometidos a diálisis en espera de transplante renal.

Palabras clave: Cáncer renal. Autotransplante. Cirugía de banco.

Summary.- OBJECTIVE: To demonstrate that "bench surgery" and autotransplantation are still alternatives in the treatment of complex renal cancer cases.

METHODS: 58 y/o female with history of radical nephrectomy due to renal cancer who asked for medical attention because of back pain. Renal masses were found during her evaluation and she was referred to our service.

RESULTADOS: Lumbar incision was the preferred approach. After removal, the kidney was irrigated with EuroCollins solution and bench surgery was performed. Cold ischemia time was 63 minutes. The kidney was transplanted into the right pelvic region. Diuresis was immediately achieved after vascular anastomosis. Lich-Gregoir ureteral implant was carried out. During the first 48 hrs no complication was reported, urine output was about $80 \mathrm{cc} /$ hour. She eventually developed renal failure and after 6 sessions of hemodialysis recovered to void in the previous volume range. She had a urinary leak that was resolved with CT-guided percutaneus drainage. Twelve months after the procedure, she has no complaints; serum creatinine is $1.6 \mathrm{mg} / \mathrm{dl}$ and CT scan shows no evidence of recurrences.

CONCLUSIONES: Bench surgery is still a therapeutic alternative for the treatment of complex renal cancer cases in order to avoid dialysis.

Keywords: Renal cancer. Autotransplantation. Bench surgery. 


\section{INTRODUCCIÓN}

La nefrectomía radical es sin duda el tratamiento de elección en el cáncer renal (1). Si bien el tratamiento del cáncer renal en pacientes con riñón contralateral normal está bien establecido, existen múltiples opciones terapéuticas en pacientes con tumores multicéntricos en riñones únicos o en tumores bilaterales con resultados satisfactorios (2). Presentamos el caso de una paciente con riñón único y cáncer renal multicéntrico que fue sometida a cirugía de banco con enucleación ex vivo y autotransplante.

\section{PRESENTACIÓN}

Mujer de 58 años con diagnóstico de cáncer de células renales tratado con nefrectomía radical derecha 13 años antes. Historia de hipertensión arterial, colecistectomía, hernioplastia umbilical, histerectomía y ooforectomía bilateral. Acude al servicio de medicina del dolor tras presentar como único síntoma lumbalgia. Durante su evaluación por estudios de imagen se realiza el hallazgo de tumoraciones en riñón izquierdo por lo que es referida a nuestro servicio. La exploración física sin datos relevantes. Tomografia axial computada (TAC) evidencia tumoraciones dependientes del polo superior y de la cara anterior y media del riñón (Figura 1A y 1C).

Se solicita AngioTAC donde se observan las tumoraciones y su irrigación sanguínea (Figura 1B). Los exámenes de inicio fueron normales, creatinina sérica de $0.8 \mathrm{mg} /$ dl. Se comenta con el servicio de nefrología y se indica nefrectomía parcial de banco con autotransplante. Previo a cirugía se coloca catéter tipo Niágara. Se realiza abordaje con lumbotomía. Se extrae pieza quirúrgica, se coloca riñón en mesa adjunta en solución fisiológica hipotérmica con hielo frappé. Se realiza perfusión con solución de EuroCollins y se realiza polectomía superior y enucleación de tumoración anterior y media (Figura $2 \mathrm{~A}$ y $2 \mathrm{~B}) \mathrm{Se}$ corrobora, por patología, bordes libres
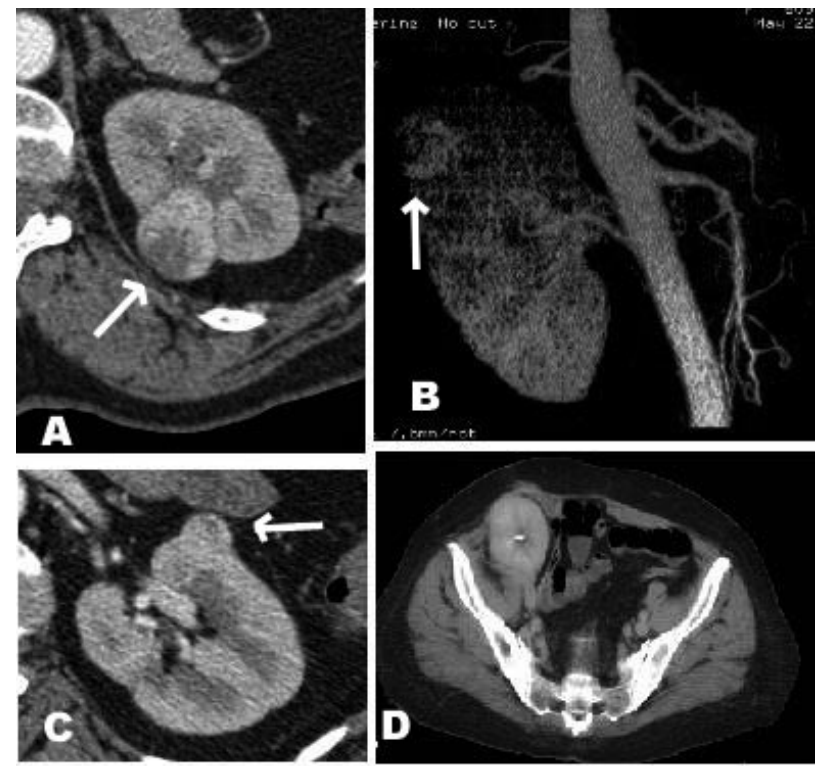

FIGURA 1. TAC contrastado donde se aprecia tumor en cara posterior del polo superior flecha (imagen A) AngioTAC (imagen B), TAC tumor cara anterior y media flecha (Imagen C), Riñón pélvico un año después (Imagen D).

de neoplasia. El tiempo de cirugía de banco antes de anastomosis vascular fue de $63 \mathrm{~min}$. Se colocó riñón en la pelvis derecha con anastomosis vascular sin complicaciones. Fue utilizada heparina $5000 \mathrm{UI}$ y Manitol. El riñón inicia diuresis inmediatamente posterior a anastomosis vascular. Se realizó reimplante ureteral tipo LichGregoir modificado y se colocó férula ureteral 8fr (Figura 2C). Cursa sus primeras 48 horas postoperatorias sin complicaciones y con diuresis en promedio de $80 \mathrm{cc}$ por hr. Posteriormente desarrolla insuficiencia renal aguda y anuria que requirió hemodiálisis. Posterior a 6 sesiones de hemodiálisis el paciente vuelve a orinar volúmenes
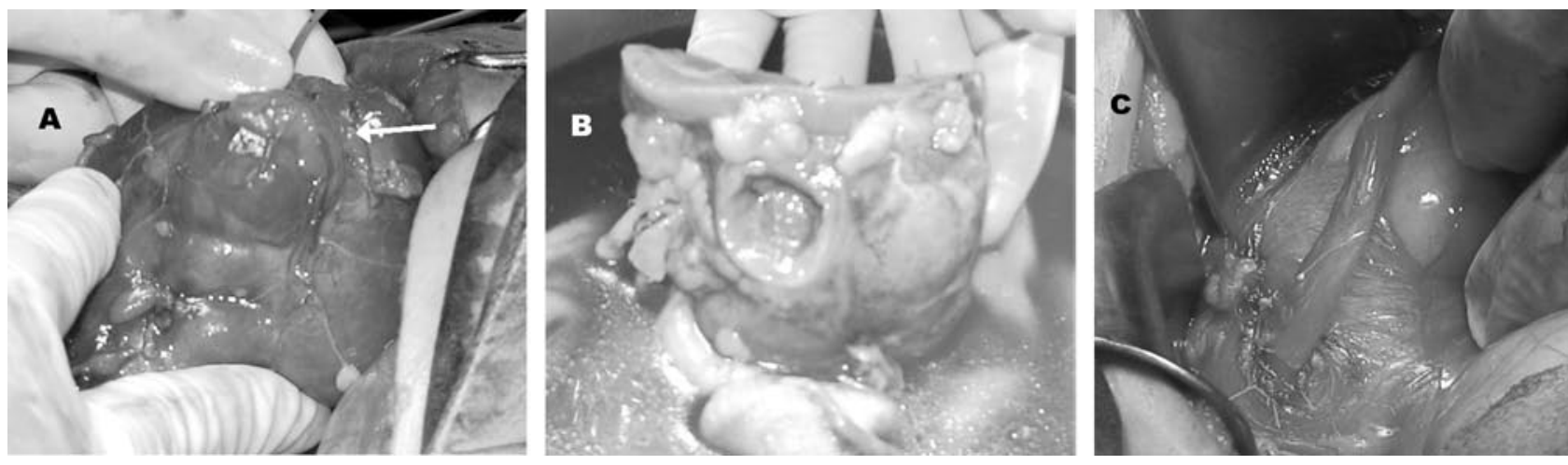

FIGURA 2. Tumor cara posterior y superior flecha (imagen A). Riñón en mesa quirúrgica posterior a polectomia superior y enucleación (imagen B), Reimplante ureteral (Imagen C). 
normales. El informe histopatológico fue un tumor de 5 $\times 3 \mathrm{~cm}$ (polo superior) y de $3.5 \times 3 \mathrm{~cm}$ (cara anterior y media) ambos con cáncer renal de células claras Fuhrman 1 con bordes libres de neoplasia.

La paciente fue egresada del hospital después de 16 días de internamiento. A los 8 días regresó al servicio de urgencias tras presentar dolor en cuadrante inferior derecho por lo que fue sometida a una nueva TAC en donde se evidenció urinoma perirrenal. Se realiza punción guiada por TAC drenando líquido amarillo claro con características físicas y químicas de orina. El cultivo fue negativo. Se deja catéter mono jota en sitio de colección y se recoloca sonda transuretral (STU). El catéter fue retirado 14 días después cuando dejó de drenar y la STU 4 días antes. Posterior a eso la paciente cursa evolución satisfactoria. Doce meses posteriores a la cirugía la depuración de creatinina fue de $60 \mathrm{ml} / \mathrm{min}$ y creatinina sérica de $1.6 \mathrm{mg} / \mathrm{dl}$.

\section{DISCUSIÓN}

El cáncer renal que se presenta en un riñón único es una indicación imperativa para realizar una cirugía que preserve la función renal (1-3). Una cirugía radical dejaría al paciente en hemodiálisis de por vida. Las opciones conservadoras ofrecen una alternativa en casos seleccionados (3-5). Existe debate sobre el tamaño indicado para realizar nefrectomía parcial electiva, pero existen reportes de que la sobrevida en pacientes con tumores entre 4 y $7 \mathrm{~cm}$ a los que se les realizó enucleación pueden alcanzar una sobrevida hasta de $81.5 \%$ en 5 años (5). Existen múltiples modalidades quirúrgicas indicadas para el tratamiento del riñón único con cáncer con diferentes resultados y complicaciones $(1,2)$ inclusive ha sido descrito en pacientes con cáncer de células transicionales de la pelvis renal pero su indicación continua siendo controversial por los resultados desalentadores $(6,7)$.

El uso de la cirugía de banco con enucleación extracorpórea de tumores multicéntricos y el eventual autotransplante se ha descrito poco en la literatura en los últimos años. Los casos que deben ser sometidos a este procedimiento deben estar meticulosamente seleccionados y sólo los pacientes con lesiones múltiples o tumores cuya resección in situ puede ser técnicamente difícil deberán ser considerados para realizar esta técnica quirúrgica (3). El autotransplante se ha descrito como técnica de elección en patología del pedículo vascular y lesiones ureterales (8).

\section{RESULTADOS}

El caso que presentamos tuvo una evolución satisfactoria y esta libre de enfermedad 12 meses posteriores al procedimiento. El seguimiento fue con TAC cada 6 meses. La cirugía de banco tiene como ventaja que se trabaja en un campo sin sangrado y que la renorrafia se realiza sin la presión del tiempo de isquemia además de tener un control tumoral más exacto (3). Si bien las complicaciones postoperatorias, como la necesidad de hemodiálisis y/o fugas urinarias han sido descritas en publicaciones anteriores, en nuestro caso pudieron resolverse de manera satisfactoria y sin repercusiones en la calidad de vida de la paciente a largo plazo.

\section{CONCLUSIÓN}

La cirugía de banco continúa siendo una opción terapéutica para casos complejos de cáncer renal para evitar que los pacientes sean sometidos a diálisis en espera de transplante renal.

\section{BIBLIOGRAFÍA Y LECTURAS RECOMENDADAS ( ${ }^{*}$ lectura de interés $y^{* *}$ lectura fundamental)}

1. UZZO, R.; NOVICK, A.C.: "Nephron sparing surgery for renal tumors: indications, techniques and outcomes". J. Urol., 166: 6, 2001.

2. GHAVAMIAN, R. y cols.: "Renal cell carcinoma in the solitary kidney: An analysis of complications and outcome after nephron sparing surgery". J. Urol., 168: 454, 2002.

*3. STORMONT, T.J.; BILHARTZ, D.L.; ZINCKE, H.: "Pitfalls of "bench surgery" and autotransplantation for renal cell carcinoma”. Mayo Clin. Proc., 67: 621, 1992.

4. BELLDEGRUN, A. y cols.: "Efficacy of nephron-sparing surgery for renal cell carcinoma: Analysis based on the new 1997 Tumor-Node-Metastasis Staging System". J. Clin. Oncol., 17: 2868, 1999.

**5. CARINI, M. y cols.: "Simple enucleation for the treatment of renal cell carcinoma between 4 and $7 \mathrm{~cm}$ in greatest dimension: Progression and long-term survival". J. Urol., 175: 2022, 2006.

6. ZINCKE, H.; SEN, S.E.: "Experience with extracorporeal surgery and autotransplantation for renal cell and transitional cell cancer of the kidney". J. Urol., 140: 25, 1988.

7. NISHIYAMA, T. y cols.: "Ex vivo partial nephrectomy and partial kidney autotransplantation for renal pelvic carcinoma in a functionally solitary kidney: Case report”. Int. J. Urol., 4: 425, 1997.

*8. LOPEZ-FANDO LAVALLE, L. y cols.: "Renal autotransplantation: A valid option in the resolution of complex cases". Arch. Esp. Urol., 60: 255, 2007. 